Meadow, P. \& KNox, R. (1956). J. gen. Microbiol. 14, 414-424

\title{
The Effect of Isonicotinic Acid Hydrazide on the Oxidative Metabolism of Mycobacterium tuberculosis \\ var. bovis B.G.G.
}

\author{
By PAULINE MEADOW* AND R. KNOX \\ Department of Bacteriology, Guy's Hospital Medical School, London, S.E. 1
}

SUMMARY : Isoniazid inhibited the oxidation of acetate in the Warburg apparatus by Mycobacterium tuberculosis B.C.G. and other mycobacteria but not by any of the other organisms tested. This effect was investigated in more detail with B.C.G. Inhibition of acetate oxidation was obtained by isoniazid whatever medium had been used for growth. The amount of isoniazid required for inhibition was related to the number of organisms present and their sensitivity to isoniazid as measured by the usual test-tube method. None of the substances reported to antagonize isoniazid inhibition was effective in annulling inhibition by isoniazid in this acetate oxidation system. The effect of various mixtures of drugs on acetate oxidation was tested. Concentrations of isoniazid and streptomycin which when used singly were insufficient to inhibit acetate oxidation, were inhibitory when used together. Similarly, mixtures of isoniazid $+p$-aminosalicylic acid (P.A.S.) or terramycin, or of streptomycin + P.A.S., at concentrations which were subinhibitory when used singly, were also effective in inhibiting acetate oxidation. It is suggested that the action of drugs or drug mixtures could usefully be investigated by this or similar techniques which have the advantage of largely eliminating the selection of resistant strains.

In a previous communication (Meadow, 1956) the effect of isonicotinic acid hydrazide (isoniazid) in inhibiting the oxidative metabolism of Mycobacterium smegmatis was described. To show any such inhibition, however, it was necessary to use high concentrations of isoniazid and carefully defined experimental conditions. Further experiments were therefore undertaken with an organism initially about 100 times more sensitive to isoniazid than $M$. smegmatis. The organism used was the attenuated strain $M$. tuberculosis var. bovis B.C.G.

\section{METHODS}

Organisms used

Mycobacterium tuberculosis var. bovis B.C.G. This was originally obtained from Dr R. J. W. Rees (National Institute for Medical Research, Mill Hill, London, N.W. 7). The parent strain was inhibited by $0.07 \mu \mathrm{g}$. isoniazid $/ \mathrm{ml}$; and an isoniazid-resistant variant, obtained by serial transfer from the highest concentration of isoniazid in which growth occurred into higher concentrations, grew in 5-10 $\mu \mathrm{g}$. isoniazid $/ \mathrm{ml}$. The strains were maintained in Dubos fluid medium, and subcultured at fortnightly intervals.

Mycobacterium smegmatis NCTC 523. The strain was maintained on nutrient agar and subcultured into Dubos fluid medium $24 \mathrm{hr}$. before use. It was inhibited by $8 \mu \mathrm{g}$. isoniazid $/ \mathrm{ml}$.

* Present address: Department of Chemical Pathology, University College Hospital Medical School, London, W.C. 1. 
Mycobacterium tuberculosis var. hominis $\mathbf{H} 37$ Ra. This was originally obtained from Dr R. J. W. Rees; it was sensitive to $0 \cdot 1 \mu \mathrm{g}$. isoniazid $/ \mathrm{ml}$. and was maintained in Dubos fluid medium.

Staphylococcus aureus Oxford NCTC 6571; Escherichia coli communius NCTC 6064; Bacillus cereus NRRL 569.

\section{Media}

The Dubos, Dubos \& Middlebrook, and fumarate media used were described previously (Meadow, 1956). Succinate medium. This was prepared as for the fumarate medium but with the sodium fumarate replaced by $0.65 \mathrm{~g}$. succinic acid. Tarshis medium (Tarshis, Kinsella \& Parker, 1953) was an agar medium containing blood, glycerol and penicillin.

\section{Sensitivity tests}

These were carried out in test tubes $\left(6 \times \frac{5}{8} \mathrm{in}\right.$.), each containing $4 \mathrm{ml}$. of Dubos fluid medium. The inoculum was 1 drop (0.02 ml.) of a 10-day culture in Dubos medium. Incubation was at $37^{\circ}$.

\section{Warburg experiments}

The cells were grown in Roux bottles, each containing $100 \mathrm{ml}$. of medium and incubated flat for 14 days at $37^{\circ}$ before reaping. The preparation and use of the cells in the Warburg apparatus have been described in a previous communication (Meadow, 1956).

\section{RESULTS}

The work described previously (Meadow, 1956) had indicated that a suitable means for studying inhibition of oxidative metabolism by isoniazid might be the oxidation of acetate by organisms grown in the absence of glucose and glycerol. In view of the specificity of low concentrations of isoniazid in inhibiting the growth only of members of the genus Mycobacterium, any system inhibited by isoniazid should be specific to mycobacteria in this respect. A small selection of organisms was tested for their ability to oxidize acetate and the effect of isoniazid on this oxidation.

\section{Organism specificity}

The organisms tested included members of the genus Mycobacterium, a staphylococcus, a strain of Bacillus cereus, and a strain of Escherichia coli whose arginine decarboxylase was sensitive to isoniazid. As shown in Table 1 only mycobacteria were inhibited; B.C.G. and H37 Ra were inhibited whether grown in the presence or absence of glucose or glycerol; Mycobacterium smegmatis showed inhibition only when grown in the absence of glucose and glycerol. The staphylococcus, Bacillus cereus and Escherichia coli strains showed no inhibition under any of the growth conditions used.

The experiments described in the sequel relate to Mycobacterium tuberculosis var. bovis B.C.G. 
Substrate specificity for B.C.G.

With washed suspensions of B.C.G. grown in a medium containing neither glucose nor glycerol, but with fumarate as sole carbon source, the effect of various substrates on their oxidative metabolism was investigated with and without the further addition of isoniazid. The substrates tested and the

Table 1. Specificity of isoniazid inhibition of acetate oxidation

\begin{tabular}{|c|c|c|c|c|c|}
\hline Organism & Growth medium & $\begin{array}{c}\text { Basal } \\
Q_{0_{2}}\end{array}$ & $\begin{array}{c}Q_{\mathrm{O}_{2}} \text { and } \\
\text { acetate } \\
10^{-1} \mathrm{M}\end{array}$ & $\begin{array}{c}Q_{\mathrm{O}_{2}} \text { and } \\
\text { acetate } 10^{-3} \mathrm{M}+ \\
\text { isoniazid } \\
2 \times 10^{-1} \mathrm{M}\end{array}$ & $\begin{array}{c}\text { Inhibition } \\
\text { by isoniazid } \\
(\%)\end{array}$ \\
\hline $\begin{array}{l}\text { Mycobacterium } \\
\text { smegmatis }\end{array}$ & $\begin{array}{l}\text { Dubos \& Middlebrook } \\
\text { Fumarate }\end{array}$ & $\begin{array}{r}14 \cdot 6 \\
4 \cdot 4\end{array}$ & $\begin{array}{r}28 \cdot 4 \\
8 \cdot 6\end{array}$ & $\begin{array}{r}28 \cdot 3 \\
6 \cdot 9\end{array}$ & $\begin{array}{r}0 \\
41\end{array}$ \\
\hline B.C.G. & $\begin{array}{l}\text { Dubos \& Middlebrook } \\
\text { Fumarate }\end{array}$ & $\begin{array}{l}7 \cdot 2 \\
1 \cdot 4\end{array}$ & $\begin{array}{r}15 \cdot 8 \\
5 \cdot 1\end{array}$ & $\begin{array}{r}12 \cdot 2 \\
3 \cdot 2\end{array}$ & $\begin{array}{l}47 \cdot 4 \\
50\end{array}$ \\
\hline $\begin{array}{l}\text { Mycobacterium } \\
\text { tuberculosis } \\
\text { H37 Ra }\end{array}$ & $\begin{array}{l}\text { Dubos \& Middlebrook } \\
\text { Fumarate }\end{array}$ & $\begin{array}{l}7 \cdot 8 \\
3 \cdot 9\end{array}$ & $\begin{array}{r}17 \cdot 6 \\
8 \cdot 3\end{array}$ & $\begin{array}{r}13 \cdot 1 \\
6 \cdot 5\end{array}$ & $\begin{array}{l}49 \\
49\end{array}$ \\
\hline $\begin{array}{l}\text { Staphylococcus } \\
\text { aureus }\end{array}$ & $\begin{array}{l}\text { Digest broth } \\
\text { Dubos \& Middlebrook } \\
\text { Fumarate }\end{array}$ & $\begin{array}{l}1 \cdot 2 \\
1 \cdot 4 \\
2 \cdot 2\end{array}$ & $\begin{array}{l}2 \cdot 61 \\
2 \cdot 8 \\
4 \cdot 6\end{array}$ & $\begin{array}{l}2 \cdot 6 \\
2 \cdot 7 \\
4 \cdot 5\end{array}$ & $\begin{array}{l}0 \\
0 \\
0\end{array}$ \\
\hline $\begin{array}{l}\text { Escherichia coli } \\
\text { communius }\end{array}$ & $\begin{array}{l}\text { Digest broth } \\
\text { Dubos \& Middlebrook } \\
\text { Fumarate }\end{array}$ & $\begin{array}{l}4 \cdot 0 \\
3 \cdot 8 \\
2 \cdot 4\end{array}$ & $\begin{array}{r}13 \cdot 0 \\
9 \cdot 1 \\
4 \cdot 9\end{array}$ & $\begin{array}{r}13 \cdot 1 \\
8 \cdot 9 \\
4 \cdot 9\end{array}$ & $\begin{array}{l}\mathbf{0} \\
\mathbf{0} \\
\mathbf{0}\end{array}$ \\
\hline Bacillus cereus & $\begin{array}{l}\text { Digest broth } \\
\text { Fumarate }\end{array}$ & $\begin{array}{l}2 \cdot 3 \\
1 \cdot 1\end{array}$ & $\begin{array}{r}10 \cdot 6 \\
7 \cdot 4\end{array}$ & $\begin{array}{r}10 \cdot 8 \\
7 \cdot 2\end{array}$ & $\begin{array}{l}\mathbf{0} \\
\mathbf{0}\end{array}$ \\
\hline
\end{tabular}

Table 2. Effect of isoniazid on the oxygen uptake of B.C.G. with various substrates

The fumarate growth medium was used throughout. Acids listed were added

\begin{tabular}{|c|c|c|c|}
\hline $\begin{array}{l}\text { Substrate added } \\
\qquad(0.01 \mathrm{M})\end{array}$ & $Q_{\mathrm{O}_{2}}$ & $\begin{array}{c}Q_{\mathrm{O}_{2}} \text { in presence } \\
\text { of isoniazid } \\
(0.001 \mathrm{M})\end{array}$ & $\begin{array}{c}\text { Inhibition } \\
\text { by isoniazid } \\
(\%)\end{array}$ \\
\hline - & $2 \cdot 4$ & $2 \cdot 4$ & 0 \\
\hline Acetate & $5 \cdot 1$ & $3 \cdot 75$ & 50 \\
\hline Glucose & $5 \cdot 1$ & $5 \cdot 2$ & $\mathbf{0}$ \\
\hline Glycerol & $4 \cdot 9$ & 4.8 & 0 \\
\hline Succinate & $2 \cdot 4$ & $2 \cdot 4$ & $\mathbf{0}$ \\
\hline Malate & $2 \cdot 35$ & $2 \cdot 35$ & o \\
\hline Fumarate & $2 \cdot 3$ & $\mathbf{2} \cdot \mathbf{3}$ & $\mathbf{0}$ \\
\hline Pyruvate & $3 \cdot 6$ & $3 \cdot 0$ & 50 \\
\hline Lactate & $4 \cdot 2$ & $\mathbf{3} \cdot \mathbf{3}$ & 50 \\
\hline Lactose & $2 \cdot 4$ & $2 \cdot 4$ & 0 \\
\hline Citrate & $2 \cdot 35$ & $\mathbf{2 \cdot 3 5}$ & $\mathbf{0}$ \\
\hline Formate & $2 \cdot 4$ & $2 \cdot 4$ & 0 \\
\hline
\end{tabular}

results are shown in Table 2 . It may be seen that the increase of $Q_{\mathrm{O}_{2}}$ above the basal rate, caused by the addition of acetate, pyruvate or lactate to the system, was approximately halved by the addition of isoniazid.

Since the stimulation of respiration by acetate was greater than that by pyruvate or lactate, and it seemed unlikely that its inhibition by isoniazid 
was due to chemical combination between the two substances, it was decided to investigate further this acetate inhibition system.

\section{Effect of different growth media on isoniazid inhibition}

In view of the different results obtained with Mycobacterium smegmatis depending on the medium used for growth, suspensions of B.C.G. which had been grown in different media were tested. Acetate oxidation was inhibited by isoniazid, whereas oxidation of glucose and glycerol was unchanged, under all the growth conditions tested (Table 3). Succinate was oxidized only when the organisms had been grown in the presence of succinate, this oxidation being partially inhibited by isoniazid. In further experiments organisms grown in the fumarate medium were used.

Table 3. Effect of isoniazid on oxidative metabolism of B.C.G. grown in different media

\begin{tabular}{|c|c|c|c|c|}
\hline Growth medium & $\begin{array}{l}\text { Substrate added } \\
(0.01 \mathrm{M})\end{array}$ & $Q_{\mathrm{O}_{2}}$ & $\begin{array}{c}Q_{\mathrm{O}_{2}} \text { in presence } \\
\text { of isoniazid } \\
(0.001 \mathrm{M})\end{array}$ & $\begin{array}{c}\text { Inhibition by } \\
\text { isoniazid } \\
(\%)\end{array}$ \\
\hline \multirow[t]{5}{*}{ Dubos } & - & $1 \cdot 98$ & $1 \cdot 99$ & 0 \\
\hline & Acetate & $16 \cdot 1$ & $\mathbf{9} \cdot \mathbf{3}$ & 50 \\
\hline & Glucose & $4 \cdot 2$ & $4 \cdot 3$ & $\mathbf{0}$ \\
\hline & Glycerol & $5 \cdot 1$ & $5 \cdot 0$ & $\mathbf{0}$ \\
\hline & Succinate & $2 \cdot 0$ & $\mathbf{2} \cdot \mathbf{0}$ & $\mathbf{0}$ \\
\hline \multirow{5}{*}{ Dubos \& Middlebrook } & - & $8 \cdot 2$ & $8 \cdot 3$ & $\mathbf{0}$ \\
\hline & Acetate & $15 \cdot 8$ & $12 \cdot 2$ & $47 \cdot 5$ \\
\hline & Glucose & $10 \cdot 4$ & $10 \cdot 3$ & 0 \\
\hline & Glycerol & $9 \cdot 8$ & $9 \cdot 9$ & 0 \\
\hline & Succinate & $8 \cdot 3$ & $8 \cdot 2$ & $\mathbf{0}$ \\
\hline \multirow[t]{5}{*}{ Tarshis } & - & $8 \cdot 5$ & $8 \cdot 6$ & $\mathbf{0}$ \\
\hline & Acetate & $26 \cdot 5$ & $16 \cdot 5$ & 45 \\
\hline & Glucose & $17 \cdot 1$ & $17 \cdot 2$ & $\mathbf{0}$ \\
\hline & Glycerol & $17 \cdot 8$ & $17 \cdot 9$ & 0 \\
\hline & Succinate & $8 \cdot 9$ & $8 \cdot 7$ & $\mathbf{0}$ \\
\hline \multirow[t]{5}{*}{ Succinate } & - & $\mathbf{3} \cdot \mathbf{8}$ & $3 \cdot 85$ & $\mathbf{0}$ \\
\hline & Acetate & $10 \cdot 4$ & $7 \cdot 1$ & 50 \\
\hline & Glucose & $10 \cdot 1$ & $10 \cdot 3$ & 0 \\
\hline & Glycerol & $12 \cdot 4$ & $12 \cdot 3$ & $\mathbf{0}$ \\
\hline & Succinate & $5 \cdot 4$ & $4 \cdot 5$ & 50 \\
\hline
\end{tabular}

Isoniazid concentration required for inhibition of acetate oxidation

The effect of adding different concentrations of isoniazid to suspensions of B.C.G. in the presence of acetate was tested. Even pre-incubation of the organisms with high concentrations of isoniazid in phosphate buffer for $24 \mathrm{hr}$. before use produced nothing greater than a $50 \%$ inhibition of acetate oxidation. The concentration of isoniazid required to produce this inhibition was dependent on the concentration of organisms present and on their sensitivity to isoniazid in growth.

Fig. 1 shows the effect of concentration of organisms on isoniazid inhibition; smaller amounts of isoniazid were required to produce $50 \%$ inhibition in the more dilute suspensions. 
Table 4 shows the relation between the amount of isoniazid required for $50 \%$ inhibition of acetate oxidation, and the sensitivity of B.C.G. as measured by growth in the test tube. It may be seen that the isoniazid-resistant strain required a much higher concentration of isoniazid to produce the same effect on acetate oxidation.

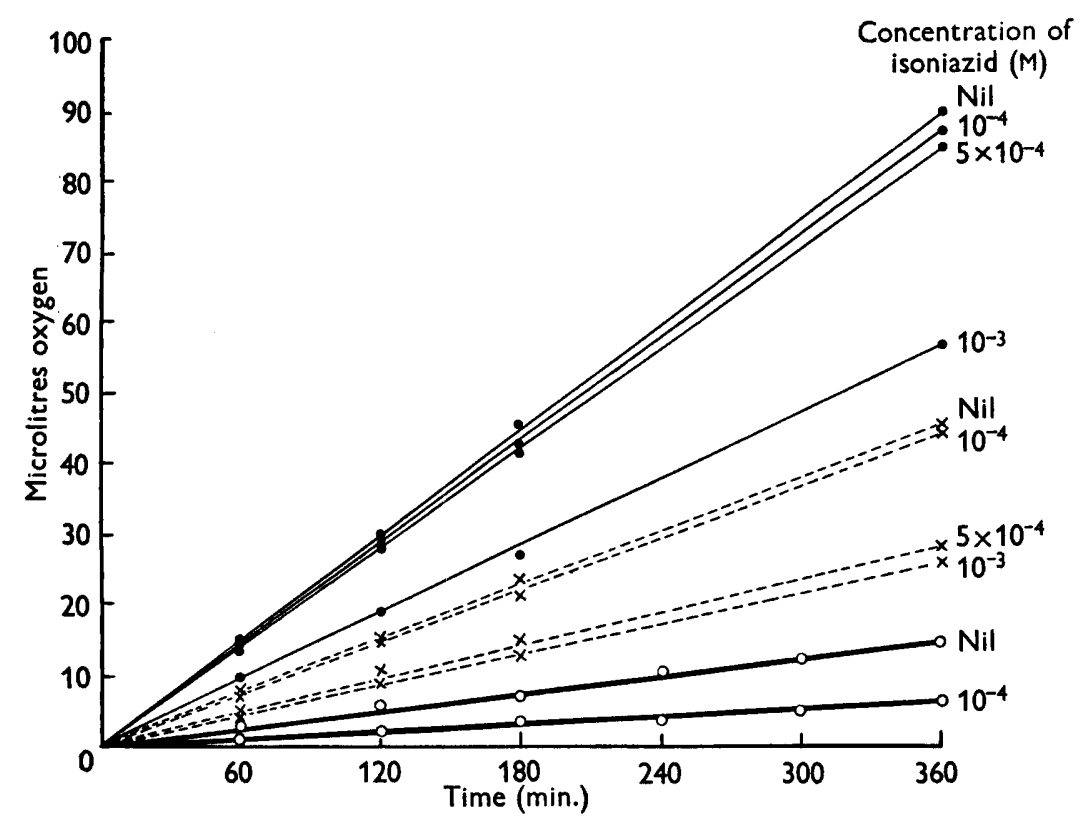

Fig. 1. Effect of cell concentration on amounts of isoniazid required to inhibit acetate oxidation by B.C.G. (S). Organisms grown in fumarate medium for 14 days, resuspended in $0 \cdot 025 \mathrm{~m}$-phosphate buffer $\mathrm{pH} 6 \cdot 8$. 0.1 $\mathrm{m}$-acetate present in each flask. $0 \cdot 3 \mathrm{ml}$. isoniazid added from the side arm. Gas phase; air. Temperature $37^{\circ}$. $\bullet-\bullet 1 \mathrm{mg}$. dry wt. organism/ml.; $\times \cdots \times, 0.5 \mathrm{mg}$. dry wt./ml.; $0-0,0.25 \mathrm{mg}$. dry wt. $/ \mathrm{ml}$.

Table 4. Relationship of isoniazid sensitivity of B.C.G. strains to inhibition of acetate oxidation by isoniazid

\begin{tabular}{|c|c|c|c|c|c|}
\hline Organism & $\begin{array}{c}\text { Concentration of } \\
\text { isoniazid required } \\
\text { to inhibit growth } \\
\text { (M) }\end{array}$ & $\begin{array}{c}\text { Substrate } \\
\text { added }\end{array}$ & $Q_{\mathrm{O}_{2}}$ & $\begin{array}{c}\text { Isoniazid added } \\
\text { to suspension in } \\
\text { Warburg vessel } \\
\text { (M) }\end{array}$ & $\begin{array}{c}\text { Inhibition by } \\
\text { isoniazid } \\
(\%)\end{array}$ \\
\hline \multirow[t]{6}{*}{ B.C.G. (S) } & $10^{-6}$ & - & $\mathbf{2 \cdot 2}$ & $\mathbf{0}$ & - \\
\hline & & Acetate & $12 \cdot 6$ & $\mathbf{o}$ & - \\
\hline & & Acetate & $12 \cdot 5$ & $10^{-4}$ & 0 \\
\hline & & Acetate & $8 \cdot 3$ & $5 \times 10^{-4}$ & 42 \\
\hline & & Acetate & $8 \cdot 0$ & $10^{-3}$ & 45 \\
\hline & & Acetate & $8 \cdot 1$ & $10^{-2}$ & 44 \\
\hline \multirow[t]{5}{*}{ B.C.G. (R) } & $10^{-4}$ & - & $1 \cdot 7$ & 0 & - \\
\hline & & Acetate & $13 \cdot 1$ & 0 & - \\
\hline & & Acetate & $13 \cdot 3$ & $10^{-2}$ & 0 \\
\hline & & Acetate & $13 \cdot 0$ & $10^{-1}$ & 0 \\
\hline & & Acetate & $7 \cdot 7$ & $3 \times 10^{-1}$ & 48 \\
\hline
\end{tabular}




\section{Antagonists of isoniazid inhibition}

There have been several reports of substances reputed to antagonize the action of isoniazid; these substances were tested as antagonists of the inhibition by isoniazid of acetate oxidation by suspensions of B.C.G.

Vitamin $B_{6}$. Yoneda, Kato \& Okajima (1952) reported that the formation of indole by Escherichia coli communius was inhibited by isoniazid, and that this inhibition was reversed by pyridoxin or pyridoxal. Yoneda \& Asano (1953) reported that the arginine decarboxylase of $E$. coli communius was also inhibited by isoniazid and that the inhibition was annulled by pyridoxal and pyridoxin. It was suggested that the similarity of their chemical structure (presence of the pyridine nucleus) might be the cause of antagonism between pyridoxin and its derivatives, on the one hand, and isoniazid.

Pyridoxin $\left(10^{-2}\right.$ to $\left.10^{-6} \mathrm{M}\right)$ and pyridoxal $\left(10^{-3}\right.$ to $\left.10^{-6} \mathrm{M}\right)$ were used in an attempt to antagonize the inhibition of acetate oxidation by isoniazid. Neither pre-treatment of the suspensions of B.C.G. with pyridoxin or pyridoxal, nor adding the vitamin with isoniazid produced any antagonism of isoniazid inhibition. Growth experiments also showed no change in the sensitivity of B.C.G. to isoniazid whether grown in the presence or absence of vita$\min B_{6}$ and its derivatives.

Manganous chloride was reported by Fisher (1954a) to annul the inhibitory action of isoniazid on the growth of Mycobacterium tuberculosis $\mathrm{H} 37 \mathrm{Rv}$ at a concentration of $0.01 \%$. No such effect was demonstrated with B.C.G. suspensions oxidizing acetate in the Warburg apparatus.

Biotin. Pitillo \& Foster (1954) reported that the inhibition by isoniazid of growth of mycobacterium A.F. 2 in broth culture was reversed by the addition of biotin to the medium. Biotin (final concentration $1 \mu \mathrm{g} . / \mathrm{ml}$.) was therefore added with isoniazid to suspensions of B.C.G. oxidizing acetate, but without effect.

Oleic acid derivatives. In view of the role of biotin in the synthesis of oleic acid (Williams, Broquist \& Snell, 1947) it was thought that isoniazid might block fatty acid production. Sodium oleate $\left(10^{-2} \mathrm{M}\right)$ and Tween 80 (a polyoxyethylene derivative of sorbitan mono-oleate, $(0 \cdot 02 \%)$, were each added to the acetate system. Neither of these substances was oxidized, nor did they have any effect on the isoniazid inhibition.

Haemin. The antagonism of isoniazid inhibition by haemin was first noticed by Fisher $(1954 a, b)$, following his discovery that some isoniazid-resistant strains in certain media required haemin as a growth factor. Under certain conditions alkaline haemin combines with isoniazid (Cohn, Oda, Kovitz \& Middlebrook, 1954; Knox, Albert \& Rees, 1955); and Gray (1953) suggested that inhibition of growth by isoniazid depends on its combination with essential porphyrin-containing enzymes, which are present in mycobacteria in very low concentration. Haemin was tested at concentrations up to $10^{-2} \mathrm{M}$ as an antagonist to isoniazid in the Warburg apparatus, both by direct addition to suspensions and by growing the B.C.G. in the presence of haemin. There was no antagonism of the inhibitory effect of isoniazid, nor did haemin stimulate 
basal oxygen uptake, nor oxygen uptake in the presence of acetate, with sensitive or resistant strains of B.C.G.

Shemin (1948) showed that glycine is involved in the synthesis of porphyrins by avian erythrocytes in vitro; Lascelles (1955) demonstrated the synthesis of porphyrins from glycine and $\alpha$-ketoglutaric acid by suspensions of Rhodospirillum spheroides. These substances were therefore added, together or singly, in the presence and absence of isoniazid, to the acetate oxidizing system, in an attempt to annul isoniazid inhibition by allowing for the synthesis of haemin during the experiment. Glycine and $\alpha$-ketoglutaric acid did not stimulate oxygen uptake, nor did they prevent inhibition of acetate oxidation by isoniazid.

Catalase. Middlebrook, Cohn \& Schaefer (1954) showed that isoniazidresistant strains were deficient in catalase, and it was thought possible that isoniazid inhibition might involve catalase activity. Catalase was tested as an antagonist of isoniazid inhibition of the acetate system but had no effect. Haemin and bovine albumin fraction $\mathrm{V} 0.002 \%(\mathrm{w} / \mathrm{v})$, singly or together, were added to B.C.G. suspensions oxidizing acetate. These substances did not increase oxygen uptake, or prevent inhibition by isoniazid.

\section{Effect of disinfectants on acetate oxidation by B.C.G. suspensions}

The effect of other antibacterial substances on the oxidation of acetate by washed suspensions of B.C.G. was tested. All the disinfectants tested were capable of causing complete inhibition of acetate oxidation. The inhibitory concentration required was the same for isoniazid-sensitive and isoniazid-resistant strains of B.C.G. (Table 5).

Table 5. Disinfectants and acetate oxidation by B.C.G.

$\begin{array}{lc} & \begin{array}{c}\text { Concentration } \\ \text { required for complete } \\ \text { inhibition } \\ (\%, w / v)\end{array} \\ \text { Disinfectant } & 0.5 \\ \text { Bradosol } & 0.05 \\ \text { Comprox A } & 0.01 \\ \text { Phenol } & 0.001 \\ \text { Cetavlon } & \end{array}$

\section{Mixtures of growth inhibitory compounds}

In view of reports of delayed emergence of resistant strains in clinical tuberculosis by the simultaneous administration of two antituberculous drugs, the effect on acetate oxidation by B.C.G. of mixtures of drugs was tested. It was found that in certain cases mixtures of drugs behaved synergistically, i.e. concentrations of drugs which alone caused no inhibition of acetate oxidation, exerted an inhibitory effect when added with subinhibitory concentrations of another drug.

The maximum inhibition of acetate oxidation obtained with any of the drugs tested was approximately $50 \%$; the effective drugs were isoniazid and 
streptomycin. Aureomycin, terramycin, achromycin, $p$-aminosalicylic acid (P.A.S.), thiosemicarbazone (T.B.1) and cyanacetic acid hydrazide (C.A.H.) had no inhibitory or stimulatory effect on the oxidation of acetate by the sensitive strain of B.C.G. As shown in Table 6, mixtures of subinhibitory concentrations of isoniazid + streptomycin, P.A.S. or terramycin, or streptomycin +P.A.S. gave a $\mathbf{5 0} \%$ inhibition of acetate oxidation. The mixtures isoniazid + C.A.H., T.B.1, aureomycin or achromycin were ineffective.

Table 6. Effect of various mixtures of anti-tuberculous drugs on oxidation of acetate by B.C.G. $(S)$

\begin{tabular}{|c|c|c|c|c|c|}
\hline \multirow[b]{2}{*}{ Drug } & \multirow{2}{*}{$\begin{array}{l}\text { Concentration } \\
\text { of drug used } \\
\text { (M) }\end{array}$} & \multicolumn{3}{|c|}{ Isoniazid concentration } & \multirow{2}{*}{$\begin{array}{l}\text { Streptomycin } \\
\quad 2 \times 10^{-2} \mathrm{M}\end{array}$} \\
\hline & & 0 & $10^{-4} \mathrm{M}$ & $5 \times 10^{-4} \mathrm{M}$ & \\
\hline \multirow{4}{*}{ Streptomycin } & - & $\mathbf{0}$ & 0 & + & $\mathbf{0}$ \\
\hline & $2 \times 10^{-1}$ & + & + & + & \\
\hline & $4 \times 10^{-2}$ & + & + & + & \\
\hline & $2 \times 10^{-2}$ & 0 & + & + & \\
\hline \multirow[t]{3}{*}{ P.A.S. } & 1 & 0 & + & + & 0 \\
\hline & $10^{-1}$ & 0 & + & + & + \\
\hline & $10^{-2}$ & $\mathbf{0}$ & + & + & + \\
\hline Terramycin & $10^{-3}$ & 0 & + & + & 0 \\
\hline Aureomycin & $10^{-3}$ & $\mathbf{0}$ & 0 & + & $\mathbf{0}$ \\
\hline Achromycin & $10^{-3}$ & $\mathbf{0}$ & 0 & + & 0 \\
\hline \multirow[t]{3}{*}{ T.B. 1} & $2 \times 10^{-1}$ & $\mathbf{0}$ & 0 & + & 0 \\
\hline & $2 \times 10^{-2}$ & 0 & $\mathbf{0}$ & + & 0 \\
\hline & $2 \times 10^{-3}$ & 0 & 0 & + & 0 \\
\hline \multirow[t]{3}{*}{ C.A.H. } & 1 & 0 & 0 & + & 0 \\
\hline & $10^{-1}$ & 0 & 0 & + & 0 \\
\hline & $10^{-2}$ & 0 & 0 & + & 0 \\
\hline
\end{tabular}

$+=47-54 \%$ inhibition of acetate oxidation; $0=$ no inhibition of acetate oxidation.

\section{DISCUSSION}

The effect of isoniazid on acetate oxidation by suspensions of B.C.G. as described above has several characteristics in common with its effect on the growth of mycobacteria. At low concentrations isoniazid is effective in inhibiting the growth of mycobacteria only, other organisms being unaffected. Similarly, of the organisms tested, only members of the genus Mycobacterium show inhibition of acetate oxidation by isoniazid. The concentration of isoniazid required to inhibit the growth of mycobacteria depends on inoculum size and the particular strain used. The growth of various strains of M. tuberculosis (both human and bovine) is inhibited by less isoniazid than the saprophytic mycobacteria such as $M$. smegmatis and $M$. phlei. In acetate oxidation the same conditions obtain; large cell concentrations require more isoniazid for inhibition than smaller ones, and $M$. tuberculosis (H37 Ra and B.C.G.) is much more sensitive to isoniazid than $M$. smegmatis. Similarly, strains of $M$. tuberculosis, which are resistant to isoniazid in growth, are also resistant to it by the acetate oxidation test. In this respect B.C.G. differs from $M$. smegmatis; the amount 
of isoniazid required to inhibit oxidation of acetate by $M$. smegmatis is not related to its sensitivity to isoniazid (Meadow, 1956).

So far it has not proved possible to determine the particular stage of acetate oxidation which is inhibited by isoniazid since the reaction has never gone to completion. By using lower concentrations of acetate and more concentrated suspensions of organisms it was hoped to achieve this effect. However, decrease of acetate concentration also decreased the rate of reaction to a marked extent and prevented the oxidation from going to completion. Similarly, increases in suspension densities increased the amount of isoniazid required for inhibition so that the range of the experiment was limited by the solubility of isoniazid.

Inhibition of pyruvate oxidation by isoniazid is probably due to chemical combination between pyruvate and isoniazid, thus effectively removing some pyruvate from the system. The hydrazone formed between isoniazid and pyruvate when tested on the system had no effect; it was not oxidized by suspensions of B.C.G. nor did it inhibit acetate oxidation. It seems unlikely, however, that isoniazid and acetate combined chemically since there was no disappearance of isoniazid from the supernatant fluid after use in the Warburg apparatus, as measured by ultraviolet spectroscopy. It appears, therefore, that this isoniazid inhibition of acetate oxidation by B.C.G. may represent fairly closely the conditions in growth inhibition.

The effectiveness of mixtures of subinhibitory concentrations of antituberculosis drugs in inhibiting the oxidation of acetate bears a resemblance to the clinical results obtained by the simultaneous administration of two drugs. The effective mixtures of drugs in the treatment of certain types of pulmonary tuberculosis appear to be: isoniazid + streptomycin, streptomycin + P.A.S., isoniazid + P.A.S. (Joiner et al. 1952, 1953; Medical Research Council, 1952, $1953 a, b)$; isoniazid + terramycin (Stewart, Turnbull \& Crofton, 1954). These are also the mixtures which are effective in the Warburg apparatus. It has been suggested that the usefulness of mixtures of drugs in the treatment of tuberculosis is partly due to suppression of the emergence of resistant strains. However, the results obtained in the Warburg apparatus indicate that another explanation must be sought, since the $6 \mathrm{hr}$. duration of the experiments would not be sufficient to allow the emergence of a resistant strain, whether or not antituberculous drugs were present. In these particular mixtures of drugs it appears that there is a genuine synergism between the members of the pairs.

The most puzzling of the results obtained concern haemin. Haemin has been shown (Knox, Albert \& Rees, 1955; Albert \& Rees, 1955; Knox \& Woodroffe, 1955) to react with isoniazid, converting it to di-isoniazid and isonicotinic acid, neither of which compounds inhibits the growth of mycobacteria except at high concentrations. Mycobacterium tuberculosis $\mathbf{H 3 7 R v}$ grows in the presence of $8 \mu \mathrm{g}$. di-isoniazid $/ \mathrm{ml}$. or $80 \mu \mathrm{g}$. isonicotinic acid $/ \mathrm{ml}$. The conversion of isoniazid to di-isoniazid or to isonicotinic acid would therefore effectively decrease the concentration of inhibitory substances present and might explain the annulment of isoniazid inhibition by haemin in growth. No such antagonism of inhibition was detected by adding haemin to the system which showed inhibition by isoniazid of acetate oxidation. This may have been due to the 
short duration of the experiment. Even under optimum conditions for isoniazid oxidation (shaking in buffer $\mathrm{pH} 7 \cdot 5$ with excess haemin) only onethird of the isoniazid present was oxidized in $24 \mathrm{hr}$. The concentration of haemin which may be added to the system in Warburg flasks is limited by its relative insolubility in phosphate buffer. Perhaps if a higher concentration could be used, the rate of reaction would be increased and some antagonism of isoniazid inhibition be detected.

We wish to thank the Guy's Hospital Endowments Fund for supporting this work.

\section{REFERENCES}

Albert, A. \& Rees, C. W. (1955). The destruction of iso-nicotinic acid hydrazide in the presence of haemin. Biochem. J. 61, 129.

Cohn, M. L., OdA, U., Kovitz, C. \& Middlebrook, G. (1954). Studies on isoniazid and tubercle bacilli. I. The isolation of isoniazid-resistant mutants in vitro. Amer. Rev. Tuberc. 70, 465.

Fisher, M. W. (1954a). Haemin as a growth factor for certain isoniazid-resistant strains of Mycobacterium tuberculosis. Amer. Rev. Tuberc. 69, 797.

Fisher, M. W. $(1954 b)$. Antagonism of the tuberculostatic action of isonicotinic acid hydrazide by haemin. Amer. Rev. Tuberc. 69, 469.

Gray, C. T. (1953). Nature of the action of isonicotinic acid hydrazide on the mycobacteria. Proc. VI Congr. int. Microbiol. 1, 179.

Joiner, C. L., Maclean, K. S., Pritchard, E. K., Anderson, K., Collard, P., King, M. B. \& KNox, R. (1952). Isoniazid in pulmonary tuberculosis. Its use with and without streptomycin. Lancet, ii, 843.

Joiner, C. L., Maclean, K. S., Chalmers, D. G., Anderson, K., Collard, P., KING, M. B. \& KNox, R. (1953). Chemotherapy of pulmonary tuberculosis. Lancet, ii, 152.

Knox, R., Albert, A. \& Rees, C. W. (1955). Destruction of isoniazid in the presence of haemin. Nature, Lond., 175, 1085.

Knox, R. \& Woodroffe, R. C. (1955). Haemin-isoniazid interaction and the effect of haemin in 'reviving' isoniazid-treated tubercle bacilli. Brit. J. exp. Path. 36, 425.

LASCELLES, J. (1955). The conversion of $\delta$-aminolaevulinic acid to porphyrins by photosynthetic bacteria. J. gen. Microbiol. 12, i.

Meadow, P. (1956). The action of isonicotinic acid hydrazide on the metabolism of Mycobacterium smegmatis. J. gen. Microbiol. 14, 414.

Medical Research Council (1952). The treatment of pulmonary tuberculosis with isoniazid. Brit. med. J. ii, 735.

Medical Research Council (1953a). Isoniazid in the treatment of pulmonary tuberculosis. Brit. med. J. i, 521.

Medical Research Council (1953b). Isoniazid in combination with streptomycin or with P.A.S. in the treatment of pulmonary tuberculosis. Brit. med. J. ii, 1005.

Middlebrook, G., Cohn, M. L. \& Schaefer, W. B. (1954). Studies on isoniazid and tubercle bacilli. III. The isolation, drug susceptibility and catalase testing of tubercle bacilli from isoniazid-treated patients. Amer. Rev. Tuberc. 70, 852 .

Pitillo, R. F. \& Foster, J. W. (1954). Potentiation of inhibitor action through determination of reversing metabolites. J. Bact. 67, 53 .

Shemin, D. (1948). The biosynthesis of porphyrins. Cold Spr. Harb. Symp. quant. Biol. 13, 185. 
Stewart, S. M., Turnbull, F. W. A. \& Crofton, J. W. (1954). The use of oxytetracycline in preventing or delaying isoniazid-resistance in pulmonary tuberculosis. Brit. med. J. ii, 1508.

Tarsirs, M. S., Kinsella, P. C. \& Parker, M. V. (1953). Blood media for the cultivation of Mycobacterium tuberculosis. VIII. Comparison of blood-agar-penicillin and Loewenstein-Jensen media under routine diagnostic conditions. J. Bact. 66, 448.

Williams, W. L., Broquist, H. P. \& Snell, E. E. (1947). Oleic acid and related compounds as growth factors for lactic acid bacteria. J. biol. Chem. 170, 619.

Yoneda, M. \& Asano, N. (1953). Pyridoxal antagonism of I.N.H. action on decarboxylase of E. coli communius. Science, 117, 277.

Yoneda, M., Kato, N. \& Okajima, M. (1952). Competitive action of isonicotinic acid hydrazide and vitamin $\mathbf{B}_{6}$ in the formation of indole by $E$. coli. Nature, Lond., 170, 803.

(Received 6 October 1955) 